\title{
VALORACIÓN ECONÓMICA DE EMPRESAS MEDIANTE LA APLICACIÓN DE FLUJOS DESCONTADOS, MODELOS DE CREACIÓN DE VALOR Y MÚLTIPLOS DE MERCADO
}

\section{Alejandro Vargas Sánchez}

\section{RESUMEN}

En el presente documento se expone la teoría de valoración económica de empresas a través de la aplicación de tres modelos financieros. El objetivo principal es mostrar la interrelación que existe entre cada uno de estos modelos a partir de variables fundamentales que explican la situación financiera de una empresa. En principio se describe el modelo de descuento de flujos de efectivo libres, posteriormente se exponen los modelos de creación de valor, para finalmente complementar el análisis con los múltiplos de mercado. La aplicación fue realizada a una empresa en la industria del cemento, la valoración obtenida con los dos primeros modelos fue similar, aunque distinta a la valoración encontrada con el modelo de múltiplos de mercado; estos resultados permiten concluir que los supuestos que se aplican a los modelos de valoración condicionan los resultados finales por lo que es necesario equiparar estos supuestos con las expectativas del mercado.

Palabras Clave: Valoración de Empresas, Descuento de Flujos, Ingresos Residuales, Beneficio Económico, Múltiplos de Mercado. 